\title{
GREENING OF INDUSTRY NETWORK NEWSLETTER
}

\section{FROM GREEENING TO SUSTAINING: TRANSFORMING CHALLENGES FOR THE FIRM}

\author{
Third Intemational Conference of \\ the Greening of Industry Network \\ November 13th-15th, 1994, Copenhagen
}

The Network's third conference brought together 170 diverse participants to study and discuss issues of industry and society in the striving for sustainability. Commentators on last year's conference remarked that the 1993 meeting seemed particularly 'harmonious', but the field is not so harmonious. This year, the Network conference took up these themes through 24 research workshops, plenary addresses and discussions - and a more personal exploration of values and perspectives - workshops on 'journeys of discovery'. The result can be described as a charged atmosphere of debate and sometimes discomfort as the body grappled with making the connections among practices, policies and differing world views. We see this tension as a healthy and natural sign of the Network's evolution, bridging many cultures into a new inter-national, inter-disciplinary, inter-organisational culture marked by openness, pluralism and concern for a sustainable future.

Keynote speaker Vandana Shiva challenged the assembly on assumptions of the benefits of industrialisation and globalisation, pointing out that industry now invades every aspect of our lives, including agriculture, health care and even reproduction. Citing this era of the dismantling of nation-states with the removal of all boundaries, geographical and ethical, Shiva condemned the free trade ideology as represented by GATT. In the ensuing debate, rebutters called for accountability and responsibility on the part of host countries, and questioned an inferred call for a return to simpler technologies.

Plenary speakers included:

- Lars Goldschmidt, Industry Division, Danish Environmental Protection Agency, who spoke on an unusual process of community participation in the selection of best available technology, sparking discussion on science and political processes.

- Claude Fussler, Dow Europe, presented Paths Toward Sustainability, The Promise of Eco-efficiency. The ensuing discussion brought out differences between ideas of incremental change and the call for envisioning a new path.

- Wout Buitelaar, University of Amsterdam, made links between Industrial Relations, Participation and Democracy, and the greening of industry.

Following the title of the conference, much of the discussion throughout the conference focused on concepts of greening and sustaining, with focus on both industry and a broader societal setting. Questions asked openly were: Are greening and sustaining the same thing? What do they have to do with Nature and the environment? Are these two concepts distinct, and one more worthy of attention, or is it possible

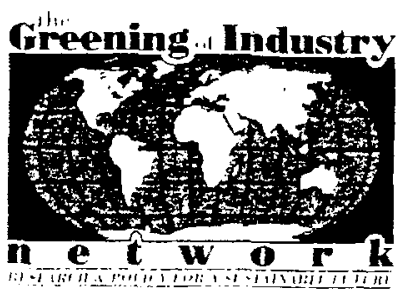

to work toward them both through different or similar means? Underlying questions over the three days included: Who is responsible for caring for the environment and ensuring progress toward a sustainable society? is it necessary to change life styles in the industrialised world as a necessary component of sustainability? Who has the power, and the responsibility to 'green' industry? What are the roles of government, business and the public? Who are the stakeholders, and how are they involved?

Discussions tended to converge on some aspects of the metaphor of sustainability: it is not a steady state or final goal, but a process; it is distinct from greening and environmental initiatives in being a more inclusive concept, covering issues of employment, poverty and equity in a global setting.

To give a personal account of the conference, we have again this year invited some participants to reflect on the conference and share their experiences - from their perspectives in different countries and representing different sectors as well

\section{Harry Fatkin \\ Polaroid Corporation, Cambridge, Massachusetts, USA}

I left the conference in Copenhagen in a reflective mood, mulling new learnings and possible insights. Shortly after arriving back in the USA, I found myself using the word 'sustainability' in a variety of conversations, to engage others. Exploration of views, begun in Copenhagen, continues as I write this.

My own view on sustainability is shaped somewhat by specific debates in the conference. It is also shaped by the recognition that, regardless of the diverse individual motives of participants, the group assembled in Copenhagen from various parts of the world had one thing in common. We share the same planet, have concerns about our stewardship and own a personal stake in 'sustainability'. The discussions were not always theoretical.

There clearly was positive energy throughout the conference, although some debates seemed unnecessarily rude at times. We are all 'actors', and I suppose it could be argued that creativity is unleashed through dramatic tension. With honest conversation as an objective, however, it doesn't seem particularly helpful when efforts at environmental improvement are minimised, or demeaned. There are weaknesses and inconsistencies in most human activity. And, what individual or organisational improvement effort won't appear to fall short of significance when viewed from the perspective of seemingly overwhelming global environmental problems? Valuing, and supporting all honest effort seems important to advancing 'sustainability'.

Tensions surrounding the sustainability debate derive, no doubt, from implicit challenges to the complex web of ethical, social, cultural, economic and political forces that currently shape the world. These and other forces were acknowledged and discussed at the conference. The Greening of Industry Network, having spent over three years in helping participants explore the notion of 'sustainability', 
is undoubtedly uncovering additional research possibilities related to the practical impact of these forces. And, knowingly or not, the Network itself is experimenting with institutional mechanisms which bring 'all actors' to one table to foster meaningful conversation, despite those forces and the underlying tension.

Which brings me back to my reflective mood. Over the course of my 20 years of environmental work within industry, my most meaningful professional experiences have resulted in my widening horizons and broadening perspectives. Those changes never occurred in isolation and were often shaped by external challenges which, in the USA, are usually posed by environmental groups. In a global sense the Network contains ingredients (challenge, tension, energy) and actors (government, industry, NGO, academic) needed for positive and pragmatic change toward 'sustainability'.

P.D. Jose

Indian Institute of Management, Ahmedabad, India

The process of transition to a sustainable industrial society is characterised by a number of underlying themes, and papers presented at the Conference explored a range of these. (Often, to my disappointment, I found that very interesting papers were being presented in different workshops at the same time). The issues debated included: a) the necessity of adopting an interdisciplinary approach when examining corporate environmentalism; b) the need to evolve definitions and concepts that resolve inconsistencies which exist in the conceptualisation and operationalisation of the sustainability paradigm; c) the need for augmenting the ethical arguments for greening with strong economic justifications, and consequently, the measurement of environmental performance and its linkage to economic performance; d) stakeholder roles in the greening process, particularly the role of governments and the academia; e) greening and its linkage to employment; $f$ the need for technology sharing between the Northern and Southern countries and the adoption of 'appropriate' rather than the 'best available' technologies; g) broadening the scope of sustainable production to cover services as well; $h$ ) greening through demand management rather than through the conventional route of supply side manipulations.

Personally, I found the papers that attempted integrating environmental management into the existing organisational literature, and those exploring the relation between ecological and economic performance to be the most interesting, as they correspond to my research interests. Papers detailing the impact of environmental issues on the corporate structures, systems and strategies also provided valuable insights and raised a number of interesting research questions.

Though much has also been written about the strong correlation between 'good' environmental and economic performance and its impact on competitiveness, most of the evidence presented earlier has been anecdotal in nature. Papers at the conference that examined this aspect have, in my opinion, made a significant contribution to this inadequately researched topic. However, much more work needs to be done in this area.
Equally important was the opportunity to interact with and learn from researchers from contexts that are quite different from the Indian (developing country) context. Environmental management has become a strategic issue for most developing countries' businesses only in the recent past. Hence, opportunities for such interaction are rather limited in our own countries.

The Network conferences provide a valuable opportunity for people with diverse backgrounds and interests to interact and exchange information and ideas. The unique strength of the conference stems from this 'open networking' approach and must continue to be preserved. However, increasing the number of participants from the emerging economies will greatly improve the breadth and relevance of the conferences. Any action plan for greening industry that excludes or limits this group can achieve only a limited success. I recommend that one of the future Network conferences be convened in one of the emerging economies. Greening would then go truly global.

\section{Ann Marie Sahagian Sustainability Branch Environment Canada, Ottawa, Canada}

The Copenhagen conference of the Greening of Industry Network was the first that I have attended and was also my first opportunity to experience and participate directly in the workings of the group. I found participation in the conference to be both stimulating and challenging.

I found the theme of the conference, 'From Greening to Sustaining...', to be reflective of a broadening of focus that has taken place not only with respect to business, but more. generally in society. Over the last 20 to 25 years, we have come to realise the cost, in human and economic terms, of environmental degradation. Ground breaking initiatives such. as the work of the Brundtland Commission and the United Nations Conference on Environment and Development (UNCED) have helped us to realise even more clearly the linkages among economic activity, environmental health and social well being. They have also helped us come to understand the difference between unsustainable growth and sustainable development.

It was the fact that the Network was addressing this broader theme, the challenge of moving business beyond greening and the traditional view of the environmenteconomy tradeoffs, that drew me to this conference. How is the challenge of sustainable development different from 'going green', and what does this mean for the firm in practical terms? What special role can industry play to advance sustainable development in society, particularly on issues such as: unsustainable patterns of production and consumption; unemployment and poverty versus sustainable livelihoods; business and the health of the community; and the broader social issue of equity?

These were some of the general questions / was looking forward to pursuing throughout the course of the conference. I found the discussions that ensued on these topics to be provoking, however. I would have liked to have heard a more prominent voice from business during these debates. Although the focus of the network is academic, I found that 
the perspectives brought to the discussion by participants from business, governments and other interest groups enriched the debate and brought a broader vision for the future direction of research and its application. I would recommend that the conference continue to encourage active participation from these groups.

In addition to these general questions, I also had a more specific and very practical interest in the results of research which could be applied to the development of more effective policies and programmes. There is tremendous potential for the academic community to contribute to our understanding of what motivates business to move towards more sustainable practices and thus influence policy and programme development. What are the barriers and disincentives to sustainable development practices in firms? What approaches have governments undertaken to influence decision making in the business and industrial sectors? Which have been most effective in changing behaviour, and why? How can government partner more effectively with business and universities to promote 'green' and sustainable industries and technologies? The papers that were the most useful to me from the perspective of policy and programme development, were those that focused more closely on these issues and most effectively made the bridge from broader concept or theory to practical application and implementation.

The academic community has a key role to play in the development of sound, objective information which can be used by policy makers to advance sustainable development. The more relevant and applicable that research is seen to be by policy makers, the more it will be brought into and thus influence the policy debate. I think that next year's conference in Toronto, with its increased focus on application of new models, implementation strategies for sustainability and implications for business and government policy development, will contribute even more effectively to that debate.

\section{CONFERENCE SUMMARY REPORT}

In keeping with our practice of documenting the conference results, we will once again produce a summary report written by two conference and Network participants. This year, Sarah Clarke, York University, Canada, and Susse Georg, Copenhagen Business School, Denmark, will write the report.

\section{GREENING OF INDUSTRY RESOURCE GUIDE AND BIBLIOGRAPHY}

We are happy to announce completion of the manuscript of the Network's next book, the resource guide and annotated bibliography. This book has a number of fundamental features which make it more than a bibliography. In both its production and use, this resource guide is designed to facilitate bridging across research disciplines and country barriers and bridging to practical application. In addition, each chapter contains not only a list of selected annotated references but also insightful introductory essays. These put the bibliographic references into the context of their fields and give the reader an overview of both the literature and authors' reasons for choosing the references they did. It has been both a trying and rewarding experience, bringing together the thinking and work of 20 authors, ten reviewers and four editors, but well worth the effort. Forthcoming from Island Press, June 1995.

\section{CONFERENCE}

Fourth International Research Conference

Research and Practice: Learning to Build Sustainable Industries for Sustainable Societies

Toronto, November 12th-14th, 1995

The conference theme is based on the recognition of the dual responsibility on the research community to enquire and to communicate with other agents in society to promote understanding of the issues around sustainable practice. The fourth conference of the Greening of Industry Network will focus on the emerging understanding of the contribution of business to sustainability and the role of research in supporting sustainable development in industry and society. The conference will use keynote addresses, plenary discussions, panel sessions, workshops and focus groups to share ideas-and to identify critical elements of the developing vision of sustainability.

Conference coordinator Professor Nigel Roome, York University, has rejeased the 1995 Call for Papers; paper proposals are due February 1, 1995. For information on the conference, contact Professor Roome or either Network Coordinator.

Greening of Industry Network Conference

Professor Nigel Roome

Haub Program in Business and the Environment

Faculty of Administrative Studies, York University

4700 Keele Street, North York, Ontario M3J 1P3

CANADA

Tel: 01014167365809 Fax: 01014167365762

email: as001450@orion.yorku.ca

Written correspondence, email and fax are preferred to telephone messages.

For further information on the Greening of Industry Network please contact:

Kurt Fischer (US Network Coordinator)

Greening of Industry Network

Center for Environmental Management

Tufts University, 177 College Avenue

Medford, Massachusetts 02155, USA.

Tel: 6176285000 ext. 5131 Fax: 6176273099

email kfischer@infonet.tufts.edu

or

Johan Schot (European Network Coordinator)

Greening of Industry Network

Centre for Studies of Science Technology \& Society

TW/RC-building, RC-310, PO Box 217, University of Twente 7500 AE Enschede, The Netherlands

Tel: 3153893344 Fax: 3153350625

email j.w.schot@wmw.utwente.nl 